Article

\title{
Biofilm Production Ability, Virulence and Antimicrobial Resistance Genes in Staphylococcus aureus from Various Veterinary Hospitals
}

\author{
Lin Chen ${ }^{1,2,3}$, Zi-Yun Tang ${ }^{1,2}$, Shi-Yun Cui ${ }^{1,2}$, Zhen-Bao Ma ${ }^{1,2}$, Hua Deng ${ }^{3}$, Wei-Li Kong ${ }^{1,2}$, \\ Li-Wen Yang ${ }^{1,2}$, Chao Lin ${ }^{1,2}$, Wen-Guang Xiong ${ }^{1,2, *}$ and Zhen-Ling Zeng ${ }^{1,2, *}$ \\ 1 Guangdong Provincial Key Laboratory of Veterinary Drugs Development and Safety Evaluation, \\ National Risk Assessment Laboratory for Antimicrobial Resistance of Animal Original Bacteria, South China \\ Agricultural University, Guangzhou 510642, China; chenl@stu.scau.edu.cn (L.C.); \\ 20182027026@stu.scau.edu.cn (Z.-Y.T.); cuisy@stu.scau.edu.cn (S.-Y.C.); \\ mazhenbao@stu.scau.edu.cn (Z.-B.M.); kongwl@stu.scau.edu.cn (W.-L.K.); \\ yanglw@stu.scau.edu.cn (L.-W.Y.); natsume@stu.scau.edu.cn (C.L.) \\ 2 Guangdong Laboratory for Lingnan Modern Agriculture, South China Agricultural University, \\ Guangzhou 510642, China \\ 3 School of Life Science and Engineering, Foshan University, Foshan 528231, China; denghua@fosu.edu.cn \\ * Correspondence: xiongwg@scau.edu.cn (W.-G.X.); zlzeng@scau.edu.cn (Z.-L.Z.); \\ Tel./Fax: +86-20-85284896 (Z.-L.Z.)
}

Received: 11 March 2020; Accepted: 25 March 2020; Published: 4 April 2020

check for

\begin{abstract}
Staphylococcus aureus (S. aureus) is one of the most clinically important zoonotic pathogens, but an understanding of the prevalence, biofilm formulation ability, virulence, and antimicrobial resistance genes of $S$. aureus from veterinary hospitals is lacking. By characterizing $S$. aureus in different origins of veterinary hospitals in Guangzhou, China, in 2019, we identified with the presence of S. aureus in pets $(17.1 \%)$, veterinarians $(31.7 \%)$, airborne dust $(19.1 \%)$, environmental surfaces $(4.3 \%)$, and medical device surfaces (10.8\%). Multilocus sequence typing (MLST) and Staphylococcus protein A (spa) typing analyses demonstrated methicillin-sensitive S. aureus (MSSA) ST398-t571, MSSA ST188-t189, and methicillin-resistant S. aureus (MRSA) ST59-t437 were the most prevalent lineage. S. aureus with similar pulsed-field gel electrophoresis (PFGE) types distributed widely in different kinds of samples. The crystal violet straining assays revealed 100\% (3/3) of MRSA ST59 and 81.8\% (9/11) of MSSA ST188 showed strong biofilm formulation ability, whereas other STs (ST1, ST5, ST7, ST15, ST88, ST398, ST3154 and ST5353) showed weak biofilm production ability. Polymerase chain reaction (PCR) confirmed the most prevalent leucocidin, staphylococcal enterotoxins, ica operon, and adhesion genes were lukD-lukE (49.0\%), sec-sel (15.7\%), icaA-icaB-icaC-icaR (100.0\%), and $f n b B$-cidA-fib-ebps-eno (100.0\%), respectively. Our study showed that the isolates with strong biofilm production ability had a higher prevalence in $c l f A, c l f B, f n b A$ and $s d r C$ genes compared to the isolates with weak biofilm production ability. Furthermore, 2 ST1-MRSA isolates with tst gene and 1 ST88-MSSA isolate with $l u k S / F-P V$ gene were detected. In conclusion, the clonal dissemination of $S$. aureus of different origins in veterinary hospitals may have occurred; the biofilm production capacity of $S$. aureus is strongly correlated with ST types; some adhesion genes such as $c l f A, c l f B, f n b A$, and $s d r C$ may pose an influence on biofilm production ability and the emergence of $l u k S / F-P V$ and $t s t$ genes in $S$. aureus from veterinary hospitals should raise our vigilance.
\end{abstract}

Keywords: Staphylococcus aureus; prevalence; biofilm; virulence; antimicrobial resistance; veterinary hospital 


\section{Introduction}

Staphylococcus aureus (S. aureus) is one of the most clinically important zoonotic pathogens, causing skin and soft tissue infections, bloodstream infections, and even life-threatening diseases with mortality rates higher than those for acquired immunodeficiency syndrome (AIDS), tuberculosis, and viral hepatitis combined [1-3]. The human nasal vestibule is the main reservoir of $S$. aureus, persistently and intermittently colonizing about $30 \%$ and $60 \%$ of the human noses, respectively [4]. The colonization is also known to be a risk factor for staphylococcal infections [3]. In addition, S. aureus strains have been found to survive for long periods on the human skin and the primary mode of transmission of S. aureus is by direct contact, usually skin-to-skin contact with a colonized or infected individual $[1,3]$. Studies have indicated that the transmission of $S$. aureus can occur from human to animal and vice versa $[5,6]$. Alarmingly, numerous cases have been reported that humans may be infected with pet-associated S. aureus $[7,8]$, and pets such as dogs and cats can serve as the reservoir of $S$. aureus $[9,10]$. Moreover, there have been increasing reports of $S$. aureus in companion animals, environmental surfaces, and humans from veterinary hospitals or households in the past few years [7-12].

S. aureus has been considered as the most common causative pathogen in surgical site infections in recent years [13]. The ability of S. aureus to infect humans and animals poses a huge burden on the healthcare system [14]. Molecular typing methods such as pulsed-field gel electrophoresis (PFGE), multilocus sequence typing (MLST), and Staphylococcus protein A (spa) typing have been widely used to track the sources and transmissions of pathogenic bacteria like $S$. aureus, thereby helping to establish the national and global epidemiological data [3].

Since Alexander Fleming discovered that penicillin has an inhibitory effect on pathogenic bacteria including S. aureus, we have ushered in the 'antibiotic era'. From 2000 to 2015, global consumption of antibiotics increased significantly, with developing countries such as South Africa, Brazil, India, and China being the most dominate consumers $[15,16]$. In particular, the major concern is that the consumption of oxazolidinones as the last-resort compounds against methicillin-resistant Staphylococcus aureus (MRSA) is rapidly increasing [15]. If there will be no corresponding policy formulation, the global consumption of antibiotics in 2030 would be up to $200 \%$ higher than in 2015 [15]. However, a major cause for alarm is the drastic rise of antibiotic resistance of $S$. aureus with the increase in the use of antibiotics [14]. The World Health Organization (WHO) has identified antibiotic resistance as one of the biggest challenges to global health and classified S. aureus as a high priority superbug for which research and development of novel antibiotics are needed urgently $[17,18]$. We should pay attention to the phenomenon that MRSA was constantly detected in companion animals and these strains generally show multidrug-resistance, significantly limiting the treatment options [9-12,19]. This multidrug resistance could be the result of careless antibiotics usage leading to wide resistance spectrum of MRSA isolated from companion animals [20].

S. aureus biofilm formation provides a unique opportunity for persistent infection, antibiotic resistance, and immune evasion [21]. The biofilm-producing pathogen S. aureus is notorious for its ability to resist treatment by forming biofilms on indwelling medical devices, resulting in persistent infections [22]. Besides, S. aureus strains within the biofilm usually show poor response to antibiotics and immune system due to an insufficient drug penetration into the biofilm's matrix and hindering the recognizable antigens present in bacterial cells, respectively [23]. The main component of S. aureus biofilm matrix is the poly-N-acetyl $\beta-1,6$ glucosamine surface polysaccharide (PNAG), synthesized by proteins encoded by the intercellular adhesion ica operon [24]. Furthermore, microbial surface components recognizing adhesive matrix molecules (MSCRAMMs) have been shown to function as extracellular matrix components during early biofilm formation [25]. Performing a phenotypic and genotypic characterization of $S$. aureus for biofilm production and analyzing their relationship with antibiotic resistance will be important for understanding the treatment failure of infections caused by S. aureus. The crystal violet dye is widely used for in-vitro biofilm quantification due to its low cost and good reproducibility [26,27]. 
S. aureus isolates can increase the pathogenicity by secreting many important virulence factors described as toxins interfering directly with the host cells, with Panton-Valentine Leucocidin (PVL) being one of the most essential, potent, and prevalent [14]. The biofilm described as toxins, toxic shock syndrome toxin (TSST), haemolysin, and staphylococcal enterotoxins (SEs) also played an important role in the life-threatening illness caused by $S$. aureus $[21,28]$. It is important to note that only a single virulence factor is difficult to function and thus cytotoxicity is often conferred only when more than one factor combined [29]. Therefore, understanding the combination of these virulence genes in S. aureus isolates from veterinary hospitals will be vital.

The pet industry is still in its early stage, but has developed rapidly in China. In recent years, the number of dogs and cats has been increasing in developing countries [9]. Keeping pets is becoming a popular lifestyle all over the world. Direct physical contact with pets occurs every day, and therefore poses a potential risk of transmitting the pathogens like S. aureus between humans and pets [9]. To the best of our knowledge, there are currently very limited studies aimed to analyze the distribution of S. aureus in veterinary hospitals in China. Therefore, we studied the distribution of S. aureus in pets, humans, medical device surfaces, environmental surfaces, and airborne dust, and analyzed the risk of transmitting S. aureus between humans and pets from veterinary hospitals in Guangzhou, Guangdong, China. Another objective of the study was to determine biofilm production ability as well as the antimicrobial resistance and virulence genes in the S. aureus isolates.

\section{Results}

\subsection{Prevalence of S. aureus}

A total of 51 (13.9\%) out of 366 samples were confirmed to be S. aureus in the present study. The number of samples collected per veterinary hospital and the prevalence of $S$. aureus in different locations are shown in Table 1. No S. aureus isolate was detected in nasal swabs of female veterinarians, infusion pump of medical device surfaces, door handles, switch and drawer of environmental surfaces, and halls with airborne dust. S. aureus carriage rate in nasal swabs of male veterinarians $(63.6 \%)$ was highest and significantly different than the female veterinarians $(0 \%, p<0.05)$. S. aureus carriage rate in skin swabs and nasal swabs of veterinarians was not significantly different $(p=0.3)$. Similarly, there is no significant difference in the detection rates of $S$. aureus in eye swabs and nasal swabs of pets $(p=0.8)$. The carriage rate of $S$. aureus in airborne dust from different locations was not significantly different $(p=0.1)$ and the highest detection rate of $S$. aureus in airborne dust from clinic room $(26.7 \%)$ was confirmed (Table 1). In addition, surgical forceps, surgical scissors, and weighing scale of medical device surfaces and desktop, chair, cage interior, and ground of environmental surfaces were found with the presence of $S$. aureus (Table 1 ). The detection rate of $S$. aureus in veterinary hospital 1, veterinary hospital 2, and veterinary hospital 3 was significantly different $(p<0.001)$ (Table 1$)$. The MRSA strains were not isolated from medical device surfaces, environmental surfaces and airborne dust, but were detected in 4 veterinarians and 1 pet (Figure 1). 
Table 1. Prevalence of Staphylococcus aureus isolated from veterinary hospitals in Guangzhou, China.

\begin{tabular}{|c|c|c|c|c|}
\hline Sampling Location & Veterinary Hospital $1^{a}$ & Veterinary Hospital $2^{b}$ & Veterinary Hospital $3^{c}$ & Total \\
\hline Veterinarians & 9/11 & $2 / 13$ & $2 / 17$ & $13 / 41$ \\
\hline Male veterinarians & $7 / 7$ & $1 / 7$ & $2 / 7$ & $10 / 21$ \\
\hline Skin swabs & $2 / 2$ & $0 / 2$ & $1 / 2$ & $3 / 10$ \\
\hline Nasal swabs & $5 / 5$ & $1 / 4$ & $1 / 2$ & $7 / 11$ \\
\hline Female veterinarians & $2 / 4$ & $1 / 6$ & 0/10 & $3 / 20$ \\
\hline Skin swabs & $2 / 2$ & $1 / 4$ & $0 / 8$ & $3 / 14$ \\
\hline Nasal swabs & $0 / 2$ & $0 / 2$ & $0 / 2$ & $0 / 6$ \\
\hline Pets & $11 / 32$ & $3 / 38$ & 0/12 & $14 / 82$ \\
\hline Dogs & $8 / 24$ & $1 / 14$ & $0 / 6$ & $9 / 44$ \\
\hline Eye swab & $4 / 12$ & $1 / 7$ & $0 / 3$ & $5 / 22$ \\
\hline Nasal swab & $4 / 12$ & $0 / 7$ & $0 / 3$ & $4 / 22$ \\
\hline Cats & $3 / 8$ & $2 / 24$ & $0 / 6$ & $5 / 38$ \\
\hline Eye swab & $2 / 4$ & $1 / 12$ & $0 / 3$ & $3 / 19$ \\
\hline Nasal swab & $2 / 4$ & $1 / 12$ & $0 / 3$ & $2 / 19$ \\
\hline Medical device surfaces & $2 / 3$ & 0/11 & $2 / 23$ & $4 / 37$ \\
\hline Infusion pump & - & $0 / 7$ & $0 / 13$ & $0 / 20$ \\
\hline Weighing scale & - & $0 / 2$ & $1 / 4$ & $1 / 6$ \\
\hline Surgical forceps & $1 / 2$ & $0 / 1$ & $1 / 3$ & $2 / 6$ \\
\hline Surgical scissors & $1 / 1$ & $0 / 1$ & $0 / 3$ & $1 / 5$ \\
\hline Environmental surfaces & $1 / 18$ & $1 / 38$ & $4 / 82$ & $6 / 138$ \\
\hline Desktop & $0 / 2$ & $1 / 13$ & $1 / 25$ & $2 / 40$ \\
\hline Chair & - & $0 / 8$ & $1 / 19$ & $1 / 27$ \\
\hline Cage interior & $1 / 14$ & $0 / 4$ & $0 / 5$ & $1 / 23$ \\
\hline Ground & $0 / 2$ & $0 / 4$ & $2 / 13$ & $2 / 19$ \\
\hline Door handle & - & $0 / 7$ & $0 / 11$ & $0 / 18$ \\
\hline Switch & - & - & $0 / 7$ & $0 / 7$ \\
\hline Drawer & - & $0 / 2$ & $0 / 2$ & $0 / 4$ \\
\hline Airborne dust & $4 / 24$ & $0 / 13$ & $9 / 31$ & $13 / 68$ \\
\hline Clinic room & $2 / 12$ & $0 / 5$ & $6 / 13$ & $8 / 30$ \\
\hline Inpatient department & $1 / 8$ & - & $0 / 5$ & $1 / 13$ \\
\hline Hall & - & $0 / 4$ & $0 / 6$ & $0 / 10$ \\
\hline B ultrasonic room & $0 / 1$ & $0 / 2$ & $1 / 4$ & $1 / 7$ \\
\hline Reception room & $1 / 3$ & $0 / 1$ & $0 / 1$ & $1 / 5$ \\
\hline Corridor & - & $0 / 1$ & $2 / 2$ & $2 / 3$ \\
\hline Total & $28 / 88$ & $6 / 113$ & $17 / 165$ & $51 / 366$ \\
\hline
\end{tabular}

a Samples were collected from April 24-26 and July 6-8 in 2019 at the veterinary hospital in Haizhu District, Guangzhou. b Samples were collected from May 22-24 and September 22-24 in 2019 at the veterinary hospital

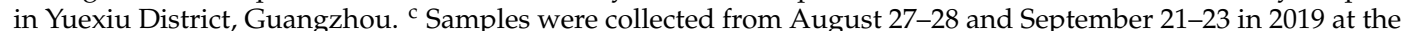
veterinary hospital in Tianhe District, Guangzhou. The bold numbers represent the isolation rate of Staphylococcus aureus from the corresponding samples. 


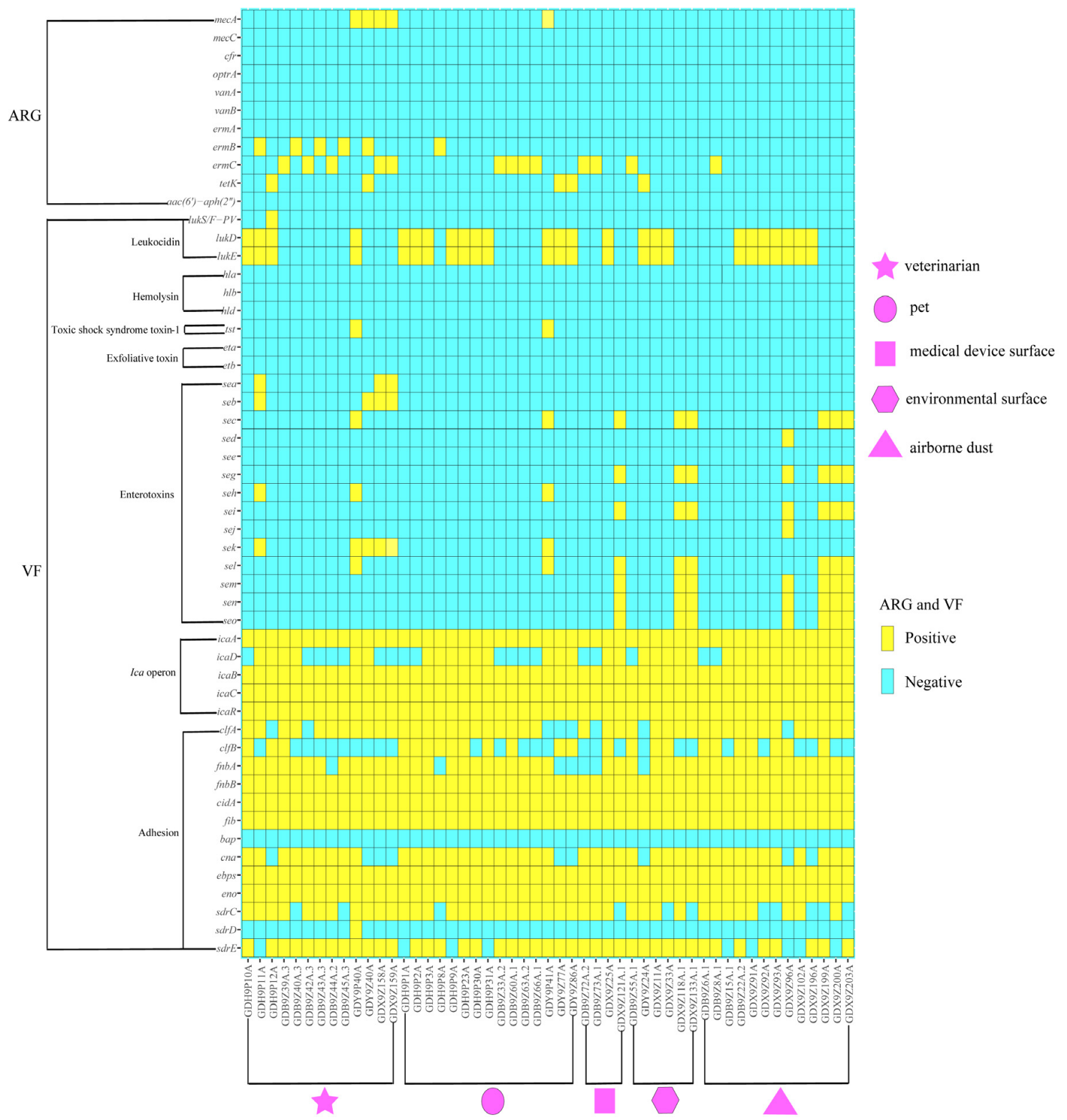

Figure 1. Antibiotic resistance genes and virulence genes profiles in S. aureus of different sources from various veterinary hospitals in Guangzhou, China. ARG and VF stand for antimicrobial resistance gene and virulence gene, respectively.

\subsection{Antimicrobial Susceptibility and Antibiotic Resistance Genes}

The antimicrobial resistance genes and antibiotic resistance profiles of $S$. aureus isolates are shown in Table 2, and Figures 1 and 2. No S. aureus isolate was resistant to oxacillin (OXA), doxycycline (DOX), tigecycline (TIG), rifampicin (RIF), vancomycin (VAN), tiamulin (TIA), fosfomycin (FOS), linezolid (LZD) or tedizolid (TZD), but $5(9.8 \%), 33(64.7 \%), 5(9.8 \%), 1(2.0 \%), 3(5.9 \%), 21(41.2 \%), 5(9.8 \%)$, $3(5.9 \%)$, and $3(5.9 \%)$ S. aureus isolates demonstrated resistance to amoxicillin (AMO), penicillin (PEN), cefoxitin (FOX), gentamycin (GEN), florfenicol (FFC), erythromycin (ERY), clindamycin (CLI), ciprofloxacin (CIP), and trimethoprim-sulfamethoxazole (SXT), respectively. In addition, 17 (33.3\%) S. aureus isolates were sensitive to all tested antibiotics (Supplementary Figure S1). S. aureus isolates from veterinarians were resistant to more antimicrobial classes than the isolates from pets, medical device surfaces, environmental surfaces and airborne dust $(p<0.001)$ (Supplementary Figure S2). The five FOX-resistant $S$. aureus isolates were found to be mecA-positive and were thus classified 
as MRSA isolates. In addition, all MRSA isolates were resistant to AMO and PEN, and thus were confirmed to be MDR isolates (Supplementary Figure S1). Attention should be paid to the phenomenon that the MRSA isolates were not resistant to OXA. Statistical analysis showed that the MRSA isolates had significantly higher resistance rates to AMO than the methicillin-susceptible S. aureus (MSSA) isolates $(100.0 \%$ vs. $0 \%, p<0.001)$, FOX $(100.0 \%$ vs. $0 \%, p<0.001)$, and CLI $(60.0 \%$ vs. $4.3 \%, p<0.05)$ (Supplementary Figure S1).

Table 2. Characteristics of S. aureus ST398 isolates.

\begin{tabular}{ccccc}
\hline Strains & Origin & Sampling Location and Time & ST-spa Typing & Resistance Phenotype \\
\hline GDH9P8A & Cat-3, nasal swab & Veterinary hospital 1, April 2019 & ST398-t571 & PEN/ERY/SXT \\
GDB9Z6A-1 & Airborne dust, clinic room-4 & Veterinary hospital 1, July 2019 & ST398-t034 & - \\
GDB9Z8A-1 & Airborne dust, clinic room-6 & Veterinary hospital 1, July 2019 & ST398-t011 & PEN/ERY \\
GDB9Z15A-1 & Airborne dust, inpatient department-4 & Veterinary hospital 1, July 2019 & ST398-t034 & - \\
GDB9Z33A-2 & Dog-7, nasal swab & Veterinary hospital 1, July 2019 & ST398-t571 & PEN/ERY \\
GDB9Z39A-3 & Male veterinarians-4, nasal swab & Veterinary hospital 1, July 2019 & ST398-t571 & PEN/ERY \\
GDB9Z40A-3 & Male veterinarians-5, nasal swab & Veterinary hospital 1, July 2019 & ST398-t034 & PEN/FFC/ERY/CIP \\
GDB9Z42A-3 & Male veterinarians-6, skin swab & Veterinary hospital 1, July 2019 & ST398-t571 & PEN/ERY \\
GDB9Z43A-3 & Male veterinarians-7, skin swab & Veterinary hospital 1, July 2019 & ST398-t034 & PEN/FFC/ERY/CIP \\
GDB9Z44A-2 & Female veterinarians-3, skin swab & Veterinary hospital 1, July 2019 & ST398-t571 & PEN/ERY \\
GDB9Z45A-3 & Female veterinarians-4, skin swab & Veterinary hospital 1, July 2019 & ST398-t034 & PEN/FFC/ERY/CIP \\
GDB9Z55A-1 & Environmental surfaces, cage interior-10 & Veterinary hospital 1, July 2019 & ST398-t571 & PEN/ERY \\
GDB9Z60A-1 & Dog-6, eye swab & Veterinary hospital 1, July 2019 & ST398-t571 & PEN/ERY \\
GDB9Z63A-2 & Dog-9, eye swab & Veterinary hospital 1, July 2019 & ST398-t571 & PEN/ERY \\
GDB9Z66A-1 & Dog-12, eye swab & Veterinary hospital 1, July 2019 & ST398-t571 & PEN/ERY \\
GDB9Z72A-2 & Medical device surfaces, surgical forceps-2 & Veterinary hospital 1, July 2019 & ST398-t571 & PEN/ERY \\
GDB9Z73A-1 & Medical device surfaces, surgical scissors-1 & Veterinary hospital 1, July 2019 & ST398-t571 & PEN/ERY \\
\hline
\end{tabular}

Resistance phenotype: “-" indicates that S. aureus isolates are sensitive to all tested antibiotics. PEN, penicillin; FFC, florfenicol, ERY, erythromycin; CIP, ciprofloxacin; SXT, trimethoprim-sulfamethoxazole.
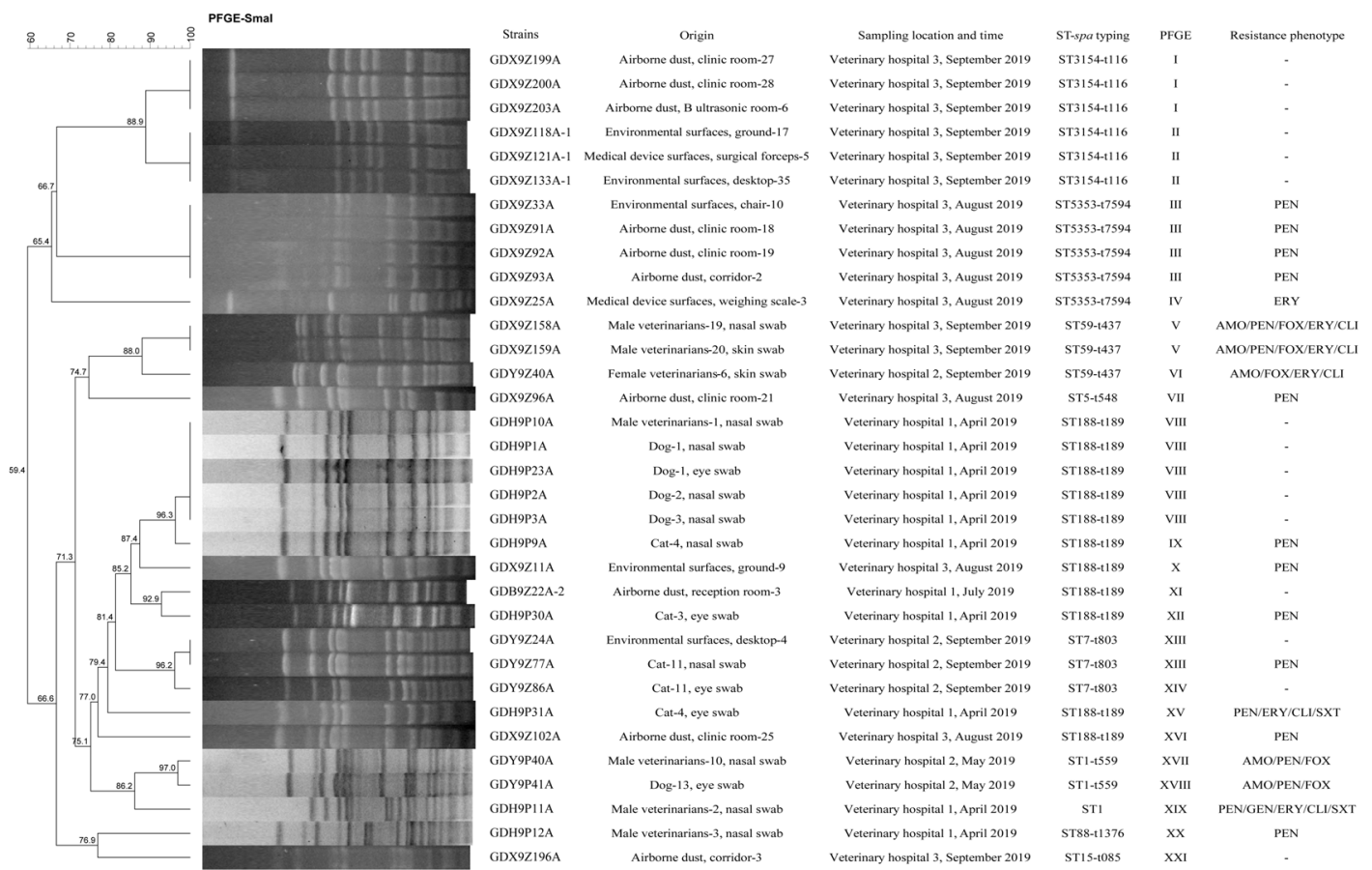

Figure 2. PFGE fingerprint patterns of $S$. aureus isolates together with ST and spa types. A similarity cutoff of $100 \%$ was used to identify a PFGE cluster. AMO, amoxicillin; PEN, penicillin; FOX, cefoxitin; ERY, erythromycin; CLI, clindamycin; SXT, trimethoprim-sulfamethoxazole; CIP, ciprofloxacin. Resistance phenotype: "-" indicates that $S$. aureus isolates are sensitive to all tested antibiotics.

All S. aureus isolates were not found with the presence of antibiotic resistance genes of $m e c C, c f r$, $\operatorname{optr} A, \operatorname{van} A, \operatorname{vanB}, \operatorname{erm} A$, and $\operatorname{aac}\left(6^{\prime}\right)$-aph (2"). The most prevalent resistance gene was $\operatorname{ermC}(25.5 \%, 13 / 51)$, followed by ermB $(11.8 \%, 6 / 51)$. The five $S$. aureus isolates carrying tetK gene were not resistant to DOX. 
Four and one mecA-positive $S$. aureus isolates were isolated from veterinarians and pets, respectively (Figures 1 and 2).

\subsection{Virulence Gene Profiles}

The frequencies of virulence genes identified in the 51 S. aureus isolates are listed in Figure 1. For leukocidin genes, 25 isolates $(49.0 \%, 25 / 51)$ harbored $l u k D$-lukE genes; one MSSA isolate $(2.0 \%, 1 / 51)$ from veterinarians harbored $l u k S / F-P V$ gene. For toxic shock syndrome toxin-1 gene, two MRSA isolates $(3.9 \%, 2 / 51)$ from veterinarians and pets had tst gene. For SEs genes, 38 isolates $(74.5 \%, 38 / 51)$ did not have any tested SEs genes; 8 isolates $(15.7 \%, 8 / 51)$ were positive for sec-sel genes; 7 (13.7\%, $7 / 51)$ isolates were positive for seg-sei-sem-sen-seo genes; 6 isolates $(11.8 \%, 6 / 51)$ were positive for sek gene; 4 isolates $(7.8 \%, 4 / 51)$ were positive for seb gene; 3 isolates $(5.9 \%, 3 / 51)$ were positive for sea gene; 3 isolates $(5.9 \%, 3 / 51)$ were positive for seh gene and one isolate $(2.0 \%, 1 / 51)$ were positive for sed-sej genes. For ica operon genes, 51 isolates $(100.0 \%, 51 / 51)$ harbored icA-icaB-icaC-icaR genes; 33 isolates $(64.7 \%, 33 / 51)$ had icaD genes. For adhesion genes, 51 isolates $(100.0 \%, 51 / 51)$ harbored fnbB-cidA-fib-ebps-eno genes; 44 isolates $(86.3 \%, 44 / 51)$ harbored $f n b A$ gene; 43 isolates $(84.3 \%, 43 / 51)$ harbored clfA gene; 42 isolates $(82.4 \%, 42 / 51)$ harbored cna gene; 42 isolates $(82.4 \%, 42 / 51)$ harbored $s d r E$ gene; 40 isolates $(78.4 \%, 40 / 51)$ harbored $s d r C$ gene; 24 isolates $(47.1 \%, 24 / 51)$ harbored $c l f B$ gene and one isolate $(2.0 \%, 1 / 51)$ harbored $s d r D$ gene. The virulence genes of $h l a, h l b, h l d$, eta, etb, see, and bap were not found in all $S$. aureus isolates (Figure 1). Based on the prevalence of the leukocidin genes, the isolates with $l u k D-l u k E$ genes had a higher prevalence in pets compared to the other sources. Based on the prevalence of the SEs genes, the sea and seb genes were detected only in S. aureus isolates from veterinarians; the sec-sel genes were detected in S. aureus isolates from all sources; the sed-sej genes were detected only in S. aureus isolates from airborne dust; the seg-sei-sem-sen-seo genes were detected in $S$. aureus isolates from medical device surfaces, environmental surfaces and airborne dust; the seh and sek genes were detected in $S$. aureus isolates from veterinarians and pets. Based on the prevalence of the ica operon and adhesion genes, the other genes except bap and $s d r D$ distributed in $S$. aureus isolates from all sources (Figure 1). Except for ica operon and adhesion genes, none of ST398 isolates harbored any texted virulence genes (Table 2 and Figure 1). All ST3154 and ST1 S. aureus isolates carried seg-sei-sem-sen-seo and seh genes, respectively (Figures 1 and 2).

\subsection{Molecular Typing and Biofilm Production Ability of S. aureus}

All S. aureus isolates represented 10 STs and ST398 $(33.3 \%, 17 / 51)$ was the most prevalent, followed by ST188 (21.6\%, 11/51), ST3154 (11.8\%, 6/51), and ST5353 (9.8\%, 5/51) (Table 2 and Figure 2). By spa typing, 12 spa types were found and the most prevalent spa types were $\mathrm{t} 189$ and $\mathrm{t} 571(21.6 \%, 11 / 51)$, followed by $\mathrm{t} 116(11.8 \%, 6 / 51), \mathrm{t7594}(9.8 \%, 5 / 51)$, and t034 (9.8\%, 5/51) (Table 2 and Figure 2). One ST1 isolate of veterinarian was confirmed non-typeable by spa typing. A strong association was observed between certain STs and spa types: ST188 was associated with t189 (100.0\%, 11/11); ST3154 was associated with $\mathrm{t} 116(100.0 \%, 6 / 6)$; ST5353 was associated with t7594 (100.0\%, 5/5); ST7 was associated with $\mathrm{t} 803(100 \%, 3 / 3)$; ST59 was associated with $\mathrm{t} 437(100.0 \%, 3 / 3)$ and ST398 was primarily associated with t571 (64.7\%, 11/17) (Table 2 and Figure 2). All non-ST398 type S. aureus isolates were successfully typed by PFGE and 21 major SmaI patterns were observed. A strong association was also observed between certain STs and PFGE types: ST188 was primarily associated with VIII (45.5\%, 5/11); ST3154 was associated mainly with I (50.0\%, 3/6) and II (50.0\%, 3/6); ST5353 was associated mainly with III $(80.0 \%, 4 / 5)$ (Figure 2). The ST188-t189-VIII pattern was found in 1 isolate from veterinarians and 4 isolates from pets. Attention should be paid to the phenomenon that MRSA isolates (GDX9Z158A and GDX9Z159A) from veterinarians in veterinary hospital 3 shared the similar PFGE types to MRSA isolate (GDY9Z40A) from veterinarians in veterinary hospital 2. Two MRSA isolates (GDY9P40A and GDY9P41A) with similar PFGE types derived from veterinarians and pets in veterinary hospital 2 were confirmed (Figure 2). In addition, S. aureus isolates (GDH9P10A from veterinarians, GDH9P1A from pets, GDX9Z11A from environmental surfaces and GDB9Z22A-2 from airborne dust) with similar 
PFGE types in veterinary hospital 1 and veterinary hospital 3 were also found (Figure 2). In the present study, $100 \%$ (3/3) of human-adapted MRSA ST59 and 81.8\% (9/11) of MSSA ST188 derived from veterinarians, pets, and airborne dust showed strong biofilm formulation ability, whereas two ST188 isolates (GDX9Z11A and GDX9Z102A) from environmental surfaces and airborne dust in veterinary hospital 3 showed weak biofilm formulation ability (Figure 3). The biofilm production ability of ST188 and ST59 was not significantly different $(p=1)$. Except for ST188 and ST59, all the S. aureus isolates with other STs showed weak biofilm production ability (Figure 3). The MRSA ST59 with strong biofilm production ability was resistant to more classes of antibiotics than MRSA ST1 with weak biofilm production ability $(p<0.001)$. However, MSSA ST398 with weak biofilm production ability showed more severe antibiotic resistance than MSSA ST188 with strong biofilm production ability $(p<0.001)$ (Table 2, Figures 2 and 3). The prevalence of adhesion genes among isolates with strong biofilm production ability was as follows: clfA (+): $100.0 \%$; clfB (+): $66.7 \%$; fnbA (+): $100.0 \%$; fnbB (+): 100.0\%; cidA (+): $100.0 \%$; fib (+): $100.0 \%$; cna (+): $100.0 \%$; ebps (+): $100.0 \%$; eno (+): $100.0 \%$; sdrC (+): $100.0 \%$, and $s d r E(+): 75.0 \%$. In contrast, the prevalence of clfA, clfB, fnbA, fnbB, cidA, fib, cna, ebps, eno, $s d r C, s d r D$, and $s d r E$ in isolates with weak biofilm production ability was $79.5 \%, 41.0 \%, 82.1 \%, 100.0 \%$, $100.0 \%, 100.0 \%, 84.6 \%, 100.0 \%, 100.0 \%, 71.8 \%, 2.6 \%$, and $84.6 \%$, respectively. As shown in Figures 1 and 3 , the isolates with strong biofilm production ability had a higher prevalence in $\operatorname{clf} A, \operatorname{clfB}, f n b A$, and $s d r C$ genes compared to the isolates with weak biofilm production ability, but this difference was not statically significant $(p=0.65)$.

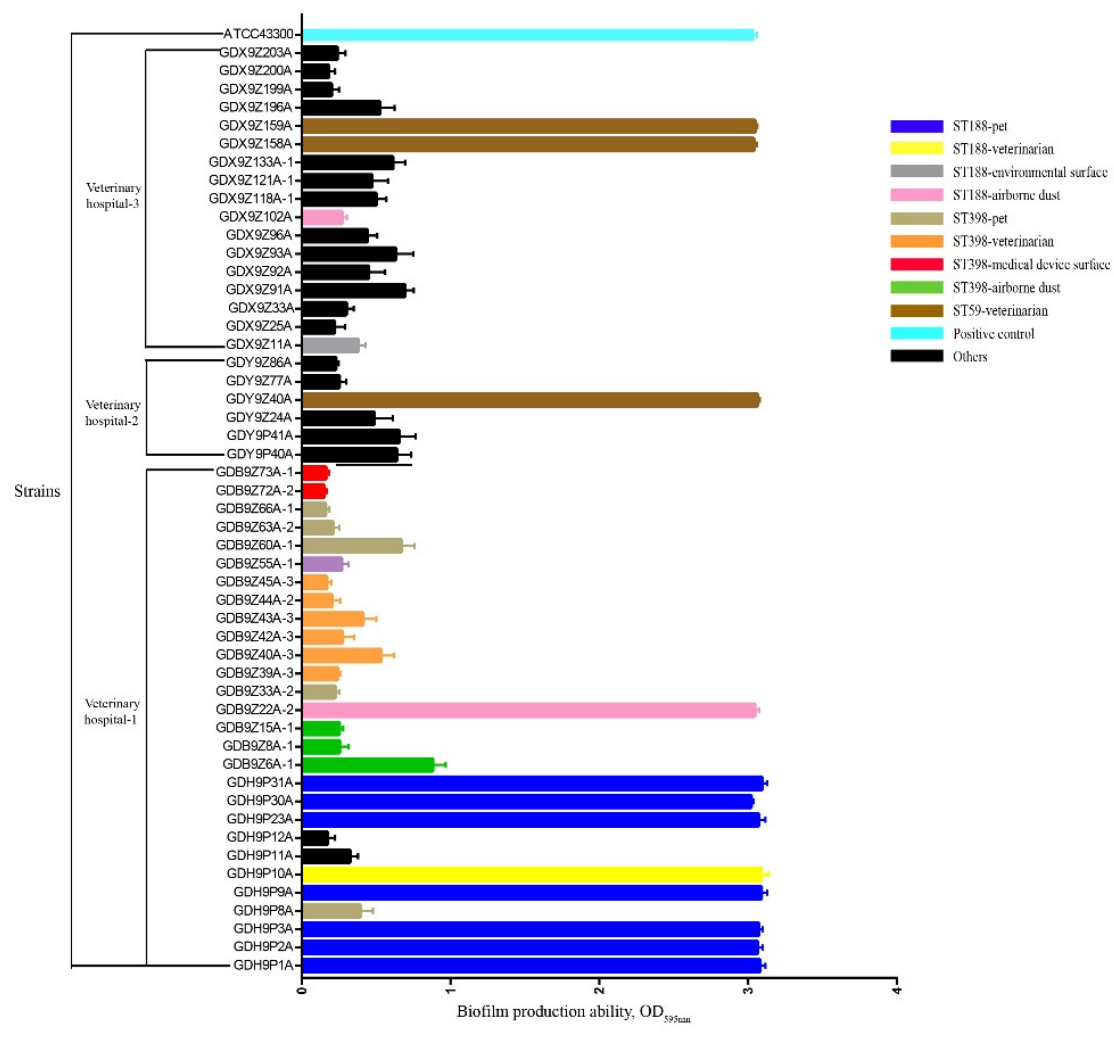

Figure 3. Biofilm production ability of $S$. aureus strains with different STs and sources determined by crystal violet straining assay after being cultured in 96-well plates at $37^{\circ} \mathrm{C}$ for $24 \mathrm{~h}$ without shaking. The total biofilm formation of $S$. aureus strains including a positive control MRSA ATCC 43300 was measured at $\mathrm{OD}_{595 \mathrm{~nm}}$. The data are the averages for eight replicates and the error bars indicate standard deviations (SDs). 


\section{Discussion}

S. aureus is an important pathogen that can cause diverse serious infections in humans and animals, posing a huge burden on the healthcare system. A relatively high recovery rate $(13.9 \%)$ of the S. aureus isolates was detected in the samples from veterinary hospitals in the present study, with different rates depending on the sample types. In addition, veterinarians and pets were found carrying MRSA. The higher detection rate of S. aureus in veterinarians $(31.7 \%)$ than that of S. aureus in other sources supports the notion that $S$. aureus is generally more host-adapted to humans [11]. It is worth noting that $S$. aureus carriage rate in nasal swabs of male veterinarians reached $63.6 \%$ and was significantly different to the female veterinarians $(0 \%, p<0.05)$. It was reported that sex and gender play an active role in the incidence of $S$. aureus bacteremia [30]. The detection rate of S. aureus in pets $(17.1 \%)$ was higher than in previous studies from China [9,31], Zambia [32], Canada [33], and Australia [34], but lower than in the previous study from Greece [35]. The frequency of MRSA in veterinarians (9.8\%) was higher in our study than in the previous study from China [9], but lower than in previous studies from Australia [11]. Regarding environmental surfaces, the studies performed in veterinary hospitals [11] and households [10] showed rates of $0 \%$ and $46 \%$ in MRSA isolates, respectively. The airborne dust and unsterilized medical device also constituted the risk of spreading S. aureus [36,37]. The present study indicated the presence of $S$. aureus in medical device surfaces, environmental surfaces, and airborne dust from veterinary hospitals, and S. aureus in airborne dust was the most prevalent (19.1\%). To our knowledge, the study to isolate and assess S. aureus strains derived from medical device surfaces, environmental surfaces, and airborne dust from veterinary hospitals is scarce. Our results added to evidence that the rate of $S$. aureus carriage in the above samples from veterinary hospitals. The contamination level of $S$. aureus in different veterinary hospitals was not the same. This may be owing to different sampling time, different numbers of sample, different geographic location of veterinary hospitals and other factors.

Our results showed that except for PEN (64.7\%) and ERY (41.2\%), the resistance rates of S. aureus to other antibiotics were less than $10 \%$. Similar results were found in S. aureus isolated from pets in Tunisia [38]. It is well known that information describing antimicrobial susceptibility patterns of MSSA isolates from veterinary hospitals is limited due to minor significance of MSSA compared with MRSA. Fortunately, all S. aureus isolates, including MRSA in this study were susceptible to TIG, LZD, TZD, and VAN, all of which are 'last resort' antibiotics for S. aureus infections. In the present study, the drug resistance of human-derived $S$. aureus was more serious than that of other sources $(p<0.001)$. This may be due to the higher proportion of MRSA in human samples than the other. The high prevalence of erm gene (ermB and ermC) in ERY-resistant $S$. aureus strains in this study was similar to that in the previous study $[9,39]$. The antibiotic resistance genes of $c f r, \operatorname{optr} A$, vanA, vanB, and $\operatorname{aac}\left(6^{\prime}\right)$-aph $\left(2^{\prime \prime}\right)$ were not detected, which was consistent with their resistant phenotypes. However, attention should be paid to the phenomenon that the mecA-carrying $S$. aureus and the tetK-carrying $S$. aureus were sensitive to OXA and DOX, respectively. The phenomenon that the strains carried resistance genes but did not show the corresponding antimicrobial resistance was easily ignored, leading to the widespread spread of pathogens and resistance genes [40,41].

The results of MLST and spa typing showed that ST188-t189 and ST398-t571 were the most prevalent in MSSA isolates, while ST59-t437 was the most prevalent in MRSA isolates. The prevalence of these strains was reported in China in previous studies [39,42,43]. Attention should be paid to the results that ST188-MSSA with similar PFGE types, ST1-MRSA with similar PFGE types, and ST398-MSSA were isolated in the samples of different sources. This indicated that the transmission of these strains among different origins may have occurred and that the pets, environmental surfaces, medical device surfaces, and airborne dust have posed a risk of spreading theses strains to humans. Three ST59-MRSA isolates of veterinarians from two veterinary hospitals with similar PFGE types should also be noted. It was reported that ST59-MRSA isolates can also be discovered from multiple host species [42]. This suggested that ST59-MRSA isolates in this study can infect humans across veterinary hospitals and were at risk of infecting pets. The prevalence of ST188-MSSA, ST398-MSSA, ST1-MRSA, and ST59-MRSA 
isolates from veterinary hospitals in the present study highlights that the distribution of these strains in China is much wider than expected. ST188 and ST398 might evolve from livestock and ST59 was the predominant clones of community-associated MRSA isolates in China [39,42]. Therefore, we suspected ST188, ST398, and ST59 may have spread from other places such as livestock and community to veterinary hospitals.

In this study, some virulence genes such as hla, hlb, hld, eta, etb, see, and bap were not found in all S. aureus isolates. However, it should be noted that two ST1-MRSA isolates carrying tst gene were isolated from pets and veterinarians, and one ST88-MSSA isolate carrying lukS/F- $P V$ gene was confirmed from veterinarians. Up to now, the tst gene has not been described in ST1-MRSA isolates from veterinary hospitals in China. The presence of tst gene in ST1-MRSA isolates from pets and veterinarians suggested that there was a risk of spreading the virulence gene among MRSA isolates from humans and pets. The ST 88 with $l u k S / F-P V$ gene were reported to cause wound infection and abscesses in humans [44]. The presence of ST88 isolates carrying lukS/F-PV gene in veterinarians reminded us that humans could be reservoirs of PVL-positive S. aureus isolates and were at risk of infecting with PVL-positive S. aureus. Most of the previous studies focused primarily on SEs causing Staphylococcal food poisoning (SFP) [45-50]. Our results showed that SEs genes (sea, seb, sed-sej, seg-sei-sem-sen-seo, seh and sek) expressed specific host specificity. For examples, the sea and seb genes were detected only in S. aureus isolates from veterinarians; the sed-sej genes were detected only in S. aureus isolates from airborne dust; the seg-sei-sem-sen-seo genes were detected only in S. aureus isolates from environmental samples (medical device surface, environmental surface, and airborne dust samples can be classed as environmental samples), and the seh and sek genes were detected only in S. aureus isolates from biological samples (veterinarian and pet samples can be classed as biological samples). Furthermore, SEs genes (sed-sej and seg-sei-sem-sen-seo) and SEs genes (seh) were significantly associated with ST3154-t116 MSSA and ST1 S. aureus isolates, respectively. The seg-sei-sem-sen-seo genes have been reported in S. aureus isolates of several specific ST types but not ST3154 [12,45]. This suggested that the seg-sei-sem-sen-seo genes are at risk of being further extended to S. aureus isolates with other ST types. Attention should be paid to the results that sec-sel genes were detected in S. aureus isolates from all sources in this study. It reminded us that the transmission of sec-sel genes in S. aureus isolates may not affected by host specificity.

The ability of $S$. aureus to produce biofilms is believed to contribute to food poisoning, antimicrobial resistance and many other problems [21,25]. An important group of virulence factors that initiate early biofilm formation steps are the MSCRAMM proteins, which are encoded by different genes such as adhesion genes [25]. For the texted 13 adhesin genes, our results showed that the detection rate of $c l f A, f n b A, f n b B, c i d A$, fib, can, ebps, eno, $s d r C$, and $s d r E$ was more than $78.4 \%$. But the bap gene was not detected in all $S$. aureus isolates from veterinary hospitals. Many previous studies reported that the bap gene was not detected in any S. aureus isolates [25,51-54]. This suggested that the bap gene is rarely prevalent in $S$. aureus according to reported articles. No difference was observed in the prevalence rate of the $f n b B$, cidA, fib, ebps, and eno genes among strong biofilm production ability and weak biofilm production ability strains. However, a previous study reported that a highly significant difference was present in the prevalence of $f n b B$, fib, ebps, and eno among these two groups [55]. Our study verified that the isolates with strong biofilm production ability had a higher prevalence in $c l f A, c l f B$, $f n b A$, and $s d r C$ genes compared to the isolates with weak biofilm production ability. This was partly consistent with the previous study, indicating that the percentage of $c l f A$ and $f n b A$ in strong biofilm production ability strains to be higher than that in weak biofilm production ability strains [56]. A second group of virulence factors that contribute to biofilm formation is ica operon [25]. Our study showed that icaA, $i c a B, i c a C$, and icaR genes were detected in all S. aureus isolates, but the prevalence of icaD gene was different between strong biofilm production ability and weak biofilm production ability strains. This differed from an earlier report that the icaD gene was detected in all S. aureus isolates [25]. Furthermore, this study firstly provided important information on the biofilm formation ability of $S$. aureus isolated from veterinary hospitals in China. A strong association was found between certain STs and biofilm 
formation ability. All human-adapted MRSA ST59 and 81.8\% (9/11) of MSSA ST188 showed strong biofilm formulation ability, whereas other STs with weak biofilm production ability were confirmed. This result was similar to the previous studies in China [42,43]. It was reported that $S$. aureus within the biofilm were poorly responsive to antibiotics and this greatly limited the choice of antibiotics for clinical treatment of S. aureus infections [23]. However, our results revealed that $S$. aureus with strong biofilm production ability cannot always show more severe resistance.

\section{Materials and Methods}

\subsection{Ethical Approval}

The study was approved by the South China Agriculture University (SCAU) Animal Ethics Committee. The field sampling protocols, samples collected from veterinary hospitals, strain isolation, and the research were conducted in in strict accordance with Section 20 of the Animal Diseases Act of 1984 (Act No 35 of 1984), Technical Guidelines for Isolation and Identification of Animal Origin Staphylococcus aureus (DB51/T 2363-2017) and the Declaration of Helsinki, and were approved with the SCAU Institutional Animal Care and Use Committee and the three veterinary hospitals (Bai Si, Yan Guo Ping and SCAU) in Guangzhou, Guangdong, China.

\subsection{Sample Collection}

A total of 366 samples were randomly collected from 3 veterinary hospitals in Guangzhou, Guangdong, China, from April 2019 to September 2019. The sampling period covered spring, summer, and autumn seasons. The samples included veterinarians ( skin swab $n=24$; nasal swab $n=17$ ), pets (eye swab $n=41$; nasal swab $n=41$ ), medical device surfaces (infusion pump $n=20$; weighing scale $n$ $=6$; surgical forceps $n=6$; surgical scissors $n=5$ ), environmental surfaces (desktop $n=40$; chair $n=29$; cage interior $n=23$; ground $n=17$; door handle $n=18$; switch $n=7$; drawer $n=4$ ), and airborne dust (clinic room $n=30$; inpatient department $n=13$; hall $n=10$; $B$ ultrasound room $n=7$; reception room $n=5$; corridor $n=3$ ) (Table 1 ). In short, sterile cotton swabs were used to collect samples from veterinarians, pets, medical device surfaces, and environmental surfaces. The Chromogenic S. aureus Agar (Guangdong Huankai Microbial Sci, Guangzhou, China) plates were used to collect airborne dust in different rooms of veterinary hospitals the whole day. These swabs were collected into sterile plastic tubes containing $1.5 \mathrm{~mL}$ of $0.85 \%$ physiological saline. Then the tubes and the plates were stored on ice during transport to the laboratory at College of Veterinary Medicine of SCAU for further analysis.

\subsection{Sample Processing and Bacterial Isolation}

The 7.5\% Sodium Chloride Broth (Guangdong Huankai Microbial Sci, Guangzhou, China) was added to the tubes and incubated for $24 \mathrm{~h}$ at $37^{\circ} \mathrm{C}$ and $180 \mathrm{rpm} / \mathrm{min}$ on a shaker. Then the treated broth was streaked onto Chromogenic S. aureus Agar plates. All the Chromogenic S. aureus Agar plates were incubated at $37^{\circ} \mathrm{C}$ for $36-48 \mathrm{~h}$. Presumptive S. aureus pure colonies (characterized by a pink color) were selected for further study.

\subsection{DNA Extraction and Molecular Identification of S. aureus}

DNA from all presumptive $S$. aureus isolates was extracted using the conventional boiling method as previously described [57]. All extracted DNA was stored at $-20^{\circ} \mathrm{C}$ until used for polymerase chain reaction (PCR) amplification. S. aureus was confirmed by amplifying a housekeeping gene nuc. S. aureus was identified as MRSA by amplifying mecA and mecC genes. PCR was performed in a $25 \mu \mathrm{L}$ reaction tube with $1 \mu \mathrm{L}$ template DNA, $2.5 \mu \mathrm{L}$ 10×rTaq Buffer $\left(\mathrm{Mg}^{2+} \mathrm{Plus}\right)$ (TaKaRa company, Dalian, China), $2 \mu \mathrm{L}$ dNTP Mixture (2.5 mM) (TaKaRa company, Dalian, China), $0.125 \mu \mathrm{L}$ TaKaRa Taq (5 U/ $\mu \mathrm{L}$ )

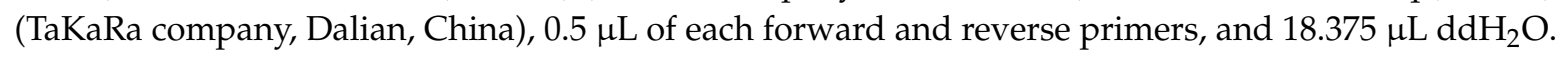
The following PCR conditions were used; $5 \mathrm{~min}$ at $94^{\circ} \mathrm{C} ; 30$ cycles of $30 \mathrm{~s}$ at $94{ }^{\circ} \mathrm{C}, 1 \mathrm{~min}$ at annealing temperature, and $1 \mathrm{~min}$ at $72{ }^{\circ} \mathrm{C}$, and final extension at $72{ }^{\circ} \mathrm{C}$ for $10 \mathrm{~min}$. Each PCR was conducted 
in triplicate using a thermocycler (BioRad, Hercules, CA, USA). PCR products were visualized on $1 \%$ agarose gel, stained with ethidium bromide, using electrophoresis for $10 \mathrm{~min}$ at 175 volts with 0.5 $\times \mathrm{TBE}$, and visualized under UV light using the Bio ChemiDoc imaging system (BioRad, California, USA). The $n u c, m e c A$, and mecC genes primers and their positive controls are shown in Supplementary Table S1. DNase free water was used as negative controls.

\subsection{Antimicrobial Susceptibility Testing}

All S. aureus isolates were investigated for their minimum inhibitory concentrations (MICs) of $\beta$-lactams (AMO, OXA, PEN, and FOX), aminoglycosides (GEN), phenicols (FFC), macrolides (ERY), lincosamides (CLI), oxazolidinones (LZD and TZD), pleuromutilins (TIA), fluoroquinolones (CIP) and DOX, TIG, RIF, SXT, VAN, and FOS by broth microdilution following the recommendations given by the Clinical and Laboratory Standards Institute (CLSI) M100-S29 and VET01-A4/VET01-S2 [58,59]. The MIC breakpoints of each antibiotic against $S$. aureus were determined following the recommendations given in the current CLSI guidance [58,59]. Multidrug resistance (MDR) was determined when an isolate was resistant to three or more antibiotics. S. aureus ATCC 29213 was used as a quality-control organism.

\subsection{Molecular Detection of Virulence and Antimicrobial Resistance Genes}

All S. aureus isolates were further screened by PCR amplification for the presence of virulence and antimicrobial resistance genes: leukocidin genes ( $l u k S / F-P V, l u k D$ and $l u k E)$, hemolysin genes ( $h l a, h l b$ and $h l d)$, the toxic shock syndrome toxin gene (tst), staphylococcal enterotoxin genes (sea, seb, sec, sed, see, seg, seh, sei, sej, sek, sel, sem, sen and seo), exfoliative toxin genes (eta and etb), ica operon genes (icaA, icaD, icaB, icaC and icaR), adhesion genes (clfA, clfB, cidA, fib, fnbA, fnbB, cna, ebps, eno, $s d r C, s d r D$ and $s d r E$ ), oxazolidinone resistance genes ( $c f r$ and optrA), vancomycin resistance genes (van $A$ and $\operatorname{van} B$ ), erythromycin resistance genes (ermA, ermB and $\operatorname{erm} C$ ), aminoglycoside resistance gene $\left(a a c\left(6^{\prime}\right)-a p h\left(2^{\prime \prime}\right)\right)$, and tetracycline resistance gene (tet $\left.K\right)$. The PCR reaction system is consistent with the reaction system used for molecular identification of S. aureus. Each PCR was conducted in triplicate using a thermocycler using a thermocycler (BioRad, California, USA). PCR products were visualized on $1 \%$ agarose gel, stained with ethidium bromide, using electrophoresis for $10 \mathrm{~min}$ at 175 volts with $0.5 \times \mathrm{TBE}$ and visualized under UV light using the Bio ChemiDoc imaging system (BioRad, California, USA). All virulence and antimicrobial resistance genes primers and their positive controls are listed in Supplementary Table S1. DNase free water was used as negative controls.

\subsection{Molecular Epidemiology Analysis}

The clonality of the S. aureus isolates was determined using the SmaI PFGE assay as described previously [60]. Comparison of PFGE patterns was performed using BioNumerics software (Applied Maths, Sint-Martens-Latem, Belgium). Dendrograms were generated using Dice similarity coefficient and a similarity cutoff of $100 \%$ was used to identify a PFGE cluster. Further identifications of clonality were performed by MLST and spa typing as described previously [61,62]. The sequences of seven housekeeping genes ( $\operatorname{arcC}$, $a r o E, g l p F, g m k$, pta, tpi, and yqiL) were submitted to the S. aureus MLST database (http://www.saureus.mlst.net/). The sequence of the polymorphic X region of the spa gene was submitted to the S. aureus spa type database (http://www.spaserver.ridom.de). Salmonella enterica serotype Braenderup H9812 DNA was used as a molecular size marker [60].

\subsection{Identification of Biofilm production Ability of S. aureus}

Biofilm production ability was identified using a microtiter plate assay as described previously [63]. S. aureus isolates were grown overnight at $37^{\circ} \mathrm{C}$ in $2 \mathrm{~mL}$ brain heart infusion (BHI) broth plus $0.25 \%$ glucose. Cultures were then diluted 1:200 and incubated at $37^{\circ} \mathrm{C}$ for $24 \mathrm{~h}$ in stationary flat-bottom 96 well polystyrene microtiter plates (Corning Incorporated, New York, NY, USA). Free cells were removed by washing the biofilm three times with sterile $1 \times \mathrm{PBS}$, dried in an inverted position, and fixed with $150 \mu \mathrm{L}$ of $\geq 99.5 \%$ methanol. The methanol was removed and the biofilm were stained with $0.1 \%$ 
crystal violet for $20 \mathrm{~min}$ at room temperature. The 96-well plates were rinsed with slow running water to remove excess crystal violet until the water became clear. Crystal violet was dissolved using ethanol/acetone (80:20) for $20 \mathrm{~min}$ and the absorbance was measured at $595 \mathrm{~nm}$. The strong biofilm forming strain MRSA ATCC 43300 was used as a positive control. The BHI broth plus $0.25 \%$ glucose was used as a negative control. Biofilm production ability was counted as follows: nonbiofilm forming $(0<\mathrm{A} 595 \leq 1)$, weak $(1<\mathrm{A} 595 \leq 2)$, moderate $(2<\mathrm{A} 595 \leq 3)$, strong (A595 > 3). All assays were performed with eight parallels and the results were processed with GraphPad Prism 8.0 software.

\subsection{Statistical Analysis}

Statistical analyses were performed using software SPSS 22.0. Data were analyzed using the chi-square or Fisher's exact tests. All statistical tests were two-tailed, and $p<0.05$ or $p<0.01$ (Fisher's exact tests among three groups) was deemed statistically significant.

\section{Conclusions}

In summary, our results revealed that $S$. aureus was not only present in veterinarians and pets but also widely distributed in the environment of veterinary hospitals. ST188-t189 and ST398-t571 were the most prevalent in MSSA isolates, while ST59-t437 was the most predominant type of MRSA isolates. Importantly, the emergence of $l u k S / F-P V$ and tst genes in S. aureus from veterinary hospitals should raise our vigilance. In addition, the relatively high antibiotic resistance rates of $S$. aureus isolates to PEN and ERY deserved our attention. The biofilm production capacity of $S$. aureus is strongly correlated with ST types and MRSA with strong biofilm production ability often showed greater drug resistance. Some adhesion genes such as $c l f A, c l f B, f n b A$, and $s d r C$ may pose an influence on biofilm production ability. Further studies are needed to elucidate the roles of these genes in the biofilm formation of S. aureus.

Supplementary Materials: The following are available online at http:/www.mdpi.com/2076-0817/9/4/264/s1, Figure S1: Antibiotic resistance in S. aureus (SA), methicillin-susceptible S. aureus (MSSA) and methicillin-resistant S. aureus (MRSA) strains from different sources of various veterinary hospitals in Guangzhou, China. Figure S2: Comparison of antibiotic resistance in S. aureus strains from veterinarians, pets, medical device surfaces, environmental surfaces and airborne dust of various veterinary hospitals in Guangzhou, China. Table S1: Primer sequences used to amplify specific virulence, antimicrobial resistance genes in this study.

Author Contributions: Conceptualization, L.C., Z.-Y.T., S.-Y.C., Z.-B.M., H.D., W.-L.K., L.-W.Y., C.L., W.-G.X., and Z.-L.Z.; methodology, L.C., H.D., W.-L.K., and L.-W.Y.; software, L.C. and Z.-B.M.; validation, W.-G.X. and Z.-L.Z.; formal analysis, L.C.; investigation, L.C., H.D., W.-L.K., L.-W.Y., and C.L.; data curation, L.C. and Z.-B.M.; writing—original draft preparation, L.C.; writing—review and editing, L.C., Z.-Y.T., S.-Y.C., Z.-B.M., H.D., W.-L.K., L.-W.Y., C.L., W.-G.X., and Z.-L.Z.; supervision and project administration, W.-G.X. and Z.-L.Z.; funding acquisition, Z.-L.Z. All authors have read and agreed to the published version of the manuscript.

Funding: This work was financially supported by the National Key R\&D Program of China (No. 2018YFD0500300).

Conflicts of Interest: The authors declare no conflicts of interest.

\section{References}

1. Wertheim, H.F.L.; Melles, D.C.; Vos, M.C.; Van Leeuwen, W.; Van Belkum, A.; Verbrugh, H.A.; Nouwen, J.L. The nasal carriage in Staphyloccocus aureus infections. Lancet Infect. Dis. 2005, 5, 751-762. [CrossRef]

2. Van Hal, S.J.; Jensen, S.O.; Vaska, V.L.; Espedido, B.A.; Paterson, D.L.; Gosbell, I.B. Predictors of mortality in Staphylococcus aureus bacteremia. Clin. Microbiol. Rev. 2012, 25, 362-386. [CrossRef] [PubMed]

3. Chambers, H.F.; Deleo, F.R. Waves of resistance: Staphylococcus aureus in the antibiotic era. Nat. Rev. Microbiol. 2009, 7, 629-641. [CrossRef] [PubMed]

4. Jenkins, A.; Diep, B.A.; Mai, T.T.; Vo, N.H.; Warrener, P.; Suzich, J.; Stover, C.K.; Sellman, B.R. Differential expression and roles of Staphylococcus aureus virulence determinants during colonization and disease. MBio 2015, 6, e02272-14. [CrossRef] [PubMed]

5. Stein, R.A. Methicillin-resistant Staphylococcus aureus-the new zoonosis. Int. J. Infect. Dis. 2009, 13, 299-301. [CrossRef] 
6. Aklilu, E.; Zakaria, Z.; Hassan, L.; Chen, H.C. Molecular relatedness of methicillin-resistant S. aureus isolates from staff, environment and pets at University Veterinary Hospital in Malaysia. PLoS ONE 2012, 7, e43329. [CrossRef]

7. Weese, J.S.; Dick, H.; Willey, B.M.; McGeer, A.; Kreiswirth, B.N.; Innis, B.; Low, D.E. Suspected transmission of methicillin-resistant Staphylococcus aureus between domestic pets and humans in veterinary clinics and in the household. Vet. Microbiol. 2006, 115, 148-155. [CrossRef]

8. Zhang, W.J.; Hao, Z.H.; Wang, Y.; Cao, X.Y.; Logue, C.M.; Wang, B.; Yang, J.; Shen, J.Z.; Wu, C.M. Molecular characterization of methicillin-resistant Staphylococcus aureus strains from pet animals and veterinary staff in China. Vet. J. 2011, 190, e125-e129. [CrossRef]

9. Bierowiec, K.; Ploneczka-Janeczko, K.; Rypula, K. Cats and dogs as a reservoir for Staphylococcus aureus. Postepy Hig. Med. Dosw. 2014, 68, 992-997. [CrossRef]

10. Hogan, P.G.; Mork, R.L.; Boyle, M.G.; Muenks, C.E.; Morelli, J.J.; Thompson, R.M.; Sullivan, M.L.; Gehlert, S.J.; Merlo, J.R.; McKenzie, M.G.; et al. Interplay of personal, pet, and environmental colonization in households affected by community-associated methicillin-resistant Staphylococcus aureus. J. Infect. 2019, 78, $200-207$. [CrossRef]

11. Worthing, K.A.; Brown, J.; Gerber, L.; Trott, D.J.; Abraham, S.; Norris, J.M. Methicillin-resistant staphylococci amongst veterinary personnel, personnel-owned pets, patients and the hospital environment of two small animal veterinary hospitals. Vet. Microbiol. 2018, 223, 79-85. [CrossRef] [PubMed]

12. Loncaric, I.; Lepuschitz, S.; Ruppitsch, W.; Trstan, A.; Andreadis, T.; Bouchlis, N.; Marbach, H.; Schauer, B.; Szostak, M.P.; Fessler, A.T.; et al. Increased genetic diversity of methicillin-resistant Staphylococcus aureus (MRSA) isolated from companion animals. Vet. Microbiol. 2019, 235, 118-126. [CrossRef] [PubMed]

13. Bai, Y.; Zhang, X.; Tian, Y.; Tian, D.; Zhang, B. Incidence of surgical-site infection following open reduction and internal fixation of a distal femur fracture. Medicine 2019, 98, e14547. [CrossRef] [PubMed]

14. Dweba, C.C.; Zishiri, O.T.; El Zowalaty, M.E. Isolation and Molecular Identification of Virulence, Antimicrobial and Heavy Metal Resistance Genes in Livestock-Associated Methicillin-Resistant Staphylococcus aureus. Pathogens 2019, 8, 79. [CrossRef] [PubMed]

15. Klein, E.Y.; Van Boeckel, T.P.; Martinez, E.M.; Pant, S.; Gandra, S.; Levin, S.A.; Goossens, H.; Laxminarayan, R. Global increase and geographic convergence in antibiotic consumption between 2000 and 2015. Proc. Natl. Acad. Sci. USA 2018, 115, E3463-E3470. [CrossRef]

16. Van Boeckel, T.P.; Gandra, S.; Ashok, A.; Caudron, Q.; Grenfell, B.T.; Levin, S.A.; Laxminarayan, R. Global antibiotic consumption 2000 to 2010: An analysis of national pharmaceutical sales data. Lancet Infect. Dis. 2014, 14, 742-750. [CrossRef]

17. Shrivastava, S.R.; Shrivastava, P.S.; Ramasamy, J. Responding to the challenge of antibiotic resistance: World Health Organization. J. Res. Med. Sci. 2018, 23, 21. [CrossRef]

18. Tartari, E.; Abbas, M.; Pires, D.; de Kraker, M.E.A.; Pittet, D. World Health Organization Save Lives: Clean Your Hands global campaign-'Fight antibiotic resistance-it's in your hands'. Clin. Microbiol. Infect. 2017, 23, 596-598. [CrossRef]

19. Gandolfi-Decristophoris, P.; Regula, G.; Petrini, O.; Zinsstag, J.; Schelling, E. Prevalence and risk factors for carriage of multi-drug resistant Staphylococci in healthy cats and dogs. J. Vet. Sci. 2013, 14, 449-456. [CrossRef]

20. Guardabassi, L.; Schwarz, S.; Lloyd, D.H. Pet animals as reservoirs of antimicrobial-resistant bacteria. J. Antimicrob. Chemother. 2004, 54, 321-332. [CrossRef]

21. Archer, N.K.; Mazaitis, M.J.; Costerton, J.W.; Leid, J.G.; Powers, M.E.; Shirtliff, M.E. Staphylococcus aureus biofilms: Properties, regulation, and roles in human disease. Virulence 2011, 2, 445-459. [CrossRef] [PubMed]

22. Moormeier, D.E.; Bayles, K.W. Staphylococcus aureus biofilm: A complex developmental organism. Mol. Microbiol. 2017, 104, 365-376. [CrossRef] [PubMed]

23. Pinto, R.M.; Lopes-de-Campos, D.; Martins, M.C.L.; Van Dijck, P.; Nunes, C.; Reis, S. Impact of nanosystems in Staphylococcus aureus biofilms treatment. FEMS Microbiol. Rev. 2019, 43, 622-641. [CrossRef]

24. Cramton, S.E.; Gerke, C.; Schnell, N.F.; Nichols, W.W.; Gotz, F. The intercellular adhesion (ica) locus is present in Staphylococcus aureus and is required for biofilm formation. Infect. Immun. 1999, 67, 5427-5433. [CrossRef]

25. Chen, Q.; Xie, S.M.; Lou, X.Q.; Cheng, S.; Liu, X.D.; Zheng, W.; Zheng, Z.B.; Wang, H.Q. Biofilm formation and prevalence of adhesion genes among Staphylococcus aureus isolates from different food sources. Microbiologyopen 2020, 9, e00946. [CrossRef] [PubMed] 
26. Boda, S.K.; Broda, J.; Schiefer, F.; Weber-Heynemann, J.; Hoss, M.; Simon, U.; Basu, B.; Jahnen-Dechent, W. Cytotoxicity of Ultrasmall Gold Nanoparticles on Planktonic and Biofilm Encapsulated Gram-Positive Staphylococci. Small 2015, 11,3183-3193. [CrossRef]

27. Liu, J.Y.; Yang, L.; Hou, Y.C.; Soteyome, T.; Zeng, B.; Su, J.Y.; Li, L.; Li, B.; Chen, D.Q.; Li, Y.Y.; et al. Transcriptomics Study on Staphylococcus aureus Biofilm Under Low Concentration of Ampicillin. Front. Microbiol. 2018, 9, 2413. [CrossRef]

28. Shukla, S.K.; Karow, M.E.; Brady, J.M.; Stemper, M.E.; Kislow, J.; Moore, N.; Wroblewski, K.; Chyou, P.-H.; Warshauer, D.M.; Reed, K.D.; et al. Virulence genes and genotypic associations in nasal carriage, community-associated methicillin-susceptible and methicillin-resistant USA400 Staphylococcus aureus isolates. J. Clin. Microbiol. 2010, 48, 3582-3592. [CrossRef]

29. Alonzo, F., 3rd; Torres, V.J. The bicomponent pore-forming leucocidins of Staphylococcus aureus. Microbiol. Mol. Biol. Rev. 2014, 78, 199-230. [CrossRef]

30. Tacconelli, E.; Foschi, F. Does gender affect the outcome of community-acquired Staphylococcus aureus bacteraemia? Clin. Microbiol. Infect. 2017, 23, 23-25. [CrossRef]

31. Boost, M.; O'Donoghue, M.; James, A. Investigation of the role of dogs as reservoirs of Staphylococcus aureus and the transmission of strains between pet owners and their dogs. Hong Kong Med. J. 2008, 14, 15-18. [PubMed]

32. Youn, J.H.; Park, Y.H.; Hang'ombe, B.; Sugimoto, C. Prevalence and characterization of Staphylococcus aureus and Staphylococcus pseudintermedius isolated from companion animals and environment in the veterinary teaching hospital in Zambia, Africa. Comp. Immunol. Microbiol. Infect. Dis. 2014, 37, 123-130. [CrossRef] [PubMed]

33. Hanselman, B.A.; Kruth, S.A.; Rousseau, J.; Weese, J.S. Coagulase positive staphylococcal colonization of humans and their household pets. Can. Vet. J. 2009, 50, 954-958. [PubMed]

34. Ma, G.C.; Worthing, K.A.; Ward, M.P.; Norris, J.M. Commensal Staphylococci Including Methicillin-Resistant Staphylococcus aureus from Dogs and Cats in Remote New South Wales, Australia. Microb. Ecol. 2019, 79, 164-174. [CrossRef]

35. Drougka, E.; Foka, A.; Koutinas, C.K.; Jelastopulu, E.; Giormezis, N.; Farmaki, O.; Sarrou, S.; Anastassiou, E.D.; Petinaki, E.; Spiliopoulou, I. Interspecies spread of Staphylococcus aureus clones among companion animals and human close contacts in a veterinary teaching hospital. A cross-sectional study in Greece. Prev. Vet. Med. 2016, 126, 190-198. [CrossRef]

36. Parisi, A.; Caruso, M.; Normanno, G.; Latorre, L.; Miccolupo, A.; Fraccalvieri, R.; Intini, F.; Manginelli, T.; Santagada, G. MRSA in swine, farmers and abattoir workers in Southern Italy. Food Microbiol. 2019, 82, 287-293. [CrossRef]

37. Ciandrini, E.; Morroni, G.; Cirioni, O.; Kamysz, W.; Kamysz, E.; Brescini, L.; Baffone, W.; Campana, R. Synergic combinations of antimicrobial peptides (AMPs) against biofilms of methicillin-resistant Staphylococcus aureus (MRSA) on polystyrene and medical devices. J. Glob. Antimicrob. Resist. 2019. [CrossRef]

38. Gharsa, H.; Ben Slama, K.; Gomez-Sanz, E.; Lozano, C.; Zarazaga, M.; Messadi, L.; Boudabous, A.; Torres, C. Molecular characterization of Staphylococcus aureus from nasal samples of healthy farm animals and pets in Tunisia. Vector Borne Zoonotic Dis. 2015, 15, 109-115. [CrossRef]

39. Li, X.; Huang, T.; Xu, K.; Li, C.; Li, Y. Molecular characteristics and virulence gene profiles of Staphylococcus aureus isolates in Hainan, China. BMC Infect. Dis. 2019, 19, 873. [CrossRef]

40. Liu, Y.; Wang, Y.; Schwarz, S.; Wang, S.L.; Chen, L.R.; Wu, C.M.; Shen, J.Z. Investigation of a multiresistance gene $c f r$ that fails to mediate resistance to phenicols and oxazolidinones in Enterococcus faecalis. J. Antimicrob. Chemother. 2014, 69, 892-898. [CrossRef]

41. Luo, R.; Zhao, L.N.; Du, P.C.; Luo, H.P.; Ren, X.; Lu, P.; Cui, S.H.; Luo, Y.P. Characterization of an Oxacillin-Susceptible mecA-Positive Staphylococcus aureus Isolate from an Imported Meat Product. Microb. Drug Resist. 2019, 26, 89-93. [CrossRef] [PubMed]

42. Wang, Y.; Liu, Q.Y.; Liu, Q.; Gao, Q.Q.; Lu, H.Y.; Meng, H.W.; Xie, Y.H.; Huang, Q.; Ma, X.W.; Wang, H.; et al. Phylogenetic analysis and virulence determinant of the host-adapted Staphylococcus aureus lineage ST188 in China. Emerg. Microbes Infect. 2018, 7, 45. [CrossRef] [PubMed]

43. Yang, X.; Qian, S.Y.; Yao, K.H.; Wang, L.J.; Liu, Y.C.; Dong, F.; Song, W.Q.; Zhen, J.H.; Zhou, W.; Xu, H.; et al. Multiresistant ST59-SCCmec IV-t437 clone with strong biofilm-forming capacity was identified predominantly in MRSA isolated from Chinese children. BMC Infect. Dis. 2017, 17, 733. [CrossRef] [PubMed] 
44. Moremi, N.; Mshana, S.E.; Kamugisha, E.; Kataraihya, J.; Tappe, D.; Vogel, U.; Lyamuya, E.F.; Claus, H. Predominance of methicillin resistant Staphylococcus aureus-ST88 and new ST1797 causing wound infection and abscesses. J. Infect. Dev. Ctries. 2012, 6, 620-625. [CrossRef]

45. Umeda, K.; Nakamura, H.; Yamamoto, K.; Nishina, N.; Yasufuku, K.; Hirai, Y.; Hirayama, T.; Goto, K.; Hase, A.; Ogasawara, J. Molecular and epidemiological characterization of staphylococcal foodborne outbreak of Staphylococcus aureus harboring seg, sei, sem, sen, seo, and selu genes without production of classical enterotoxins. Int. J. Food Microbiol. 2017, 256, 30-35. [CrossRef]

46. Wu, Y.H.; Li, J.; Qiao, M.F.; Meng, D.; Meng, Q.L.; Qiao, J.; Zhang, X.X.; Wang, L.X.; Cai, K.J.; Zhang, J.S.; et al. Characteristic profiles of biofilm, enterotoxins and virulence of Staphylococcus aureus isolates from dairy cows in Xinjiang Province, China. J. Vet. Sci. 2019, 20, e74. [CrossRef]

47. Mahfoozi, A.; Shirzad-Aski, H.; Kaboosi, H.; Ghaemi, E.A. Identification of the classical enterotoxin genes of Staphylococcus aureus in various foods by multiplex PCR assay. Iran. J. Vet. Res. 2019, 20, 209-212.

48. Azara, E.; Longheu, C.; Sanna, G.; Tola, S. Biofilm Formation and virulence factor analysis of Staphylococcus aureus isolates collected from ovine mastitis. J. Appl. Microbiol. 2017, 123, 372-379. [CrossRef]

49. Hait, J.; Tallent, S.; Melka, D.; Keys, C.; Bennett, R. Prevalence of enterotoxins and toxin gene profiles of Staphylococcus aureus isolates recovered from a bakery involved in a second staphylococcal food poisoning occurrence. J. Appl. Microbiol. 2014, 117, 866-875. [CrossRef]

50. Aydin, A.; Sudagidan, M.; Muratoglu, K. Prevalence of staphylococcal enterotoxins, toxin genes and genetic-relatedness of foodborne Staphylococcus aureus strains isolated in the Marmara region of Turkey. Int. J. Food Microbiol. 2011, 148, 99-106. [CrossRef]

51. Azmi, K.; Qrei, W.; Abdeen, Z. Screening of genes encoding adhesion factors and biofilm production in methicillin resistant strains of Staphylococcus aureus isolated from Palestinian patients. BMC Genomics 2019, 20, 578. [CrossRef] [PubMed]

52. Khoramian, B.; Jabalameli, F.; Niasari-Naslaji, A.; Taherikalani, M.; Emaneini, M. Comparison of virulence factors and biofilm formation among Staphylococcus aureus strains isolated from human and bovine infections. Microb. Pathog. 2015, 88, 73-77. [CrossRef] [PubMed]

53. Tang, J.; Chen, J.; Li, H.; Zeng, P.; Li, J. Characterization of adhesin genes, staphylococcal nuclease, hemolysis, and biofilm formation among Staphylococcus aureus strains isolated from different sources. Foodborne Pathog. Dis. 2013, 10, 757-763. [CrossRef] [PubMed]

54. Vazquez-Sanchez, D.; Habimana, O.; Holck, A. Impact of food-related environmental factors on the adherence and biofilm formation of natural Staphylococcus aureus isolates. Curr. Microbiol. 2013, 66, 110-121. [CrossRef] [PubMed]

55. Emaneini, M.; Khoramrooz, S.S.; Shahsavan, S.; Dabiri, H.; Jabalameli, F. Prevalence of panton-valentine leucocidin and phenotypic and genotypic characterization of biofilm formation among Staphylococcus aureus strains isolated from children with adenoid hypertrophy. Microb. Pathog. 2015, 89, 140-153. [CrossRef] [PubMed]

56. Rahimi, F.; Katouli, M.; Karimi, S. Biofilm production among methicillin resistant Staphylococcus aureus strains isolated from catheterized patients with urinary tract infection. Microb. Pathog. 2016, 98, 69-76. [CrossRef] [PubMed]

57. Dibbern, A.G.; Botaro, B.G.; Viziack, M.P.; Silva, L.F.; Santos, M.V. Evaluation of methods of DNA extraction from Staphylococcus aureus in milk for use in real-time PCR. Genet Mol. Res. 2015, 14, 227-233. [CrossRef] [PubMed]

58. Clinical and Laboratory Standards Institute [CLSI]. Performance Standards for Antimicrobial Susceptibility Testing; CLSI Document M100-S29; CLSI: Wayne, PA, USA, 2019.

59. Clinical and Laboratory Standards Institute [CLSI]. Performance Standards for Antimicrobial Disk and Dilution Susceptibility Tests For bacteria Isolated from Animals; Approved Standard; VET01-A4/VET01-S2; CLSI: Wayne, PA, USA, 2013.

60. Tenover, F.C.; Arbeit, R.D.; Goering, R.V.; Mickelsen, P.A.; Murray, B.E.; Persing, D.H.; Swaminathan, B. Interpreting chromosomal DNA restriction patterns produced by pulsed-field gel electrophoresis: Criteria for bacterial strain typing. J. Clin. Microbiol. 1995, 33, 2233-2239. [CrossRef]

61. Antoci, E.; Pinzone, M.R.; Nunnari, G.; Stefani, S.; Cacopardo, B. Prevalence and molecular characteristics of methicillin-resistant Staphylococcus aureus (MRSA) among subjects working on bovine dairy farms. Infez Med. 2013, 21, 125-129. 
62. Armand-Lefevre, L.; Ruimy, R.; Andremont, A. Clonal comparison of Staphylococcus aureus isolates from healthy pig farmers, human controls, and pigs. Emerg. Infect. Dis. 2005, 11, 711-714. [CrossRef]

63. Jahanshahi, A.; Zeighami, H.; Haghi, F. Molecular Characterization of Methicillin and Vancomycin Resistant Staphylococcus aureus Strains Isolated from Hospitalized Patients. Microb. Drug Resist. 2018, 24, 1529-1536. [CrossRef] [PubMed]

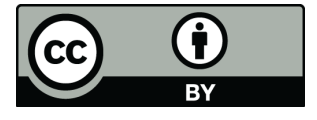

(C) 2020 by the authors. Licensee MDPI, Basel, Switzerland. This article is an open access article distributed under the terms and conditions of the Creative Commons Attribution (CC BY) license (http://creativecommons.org/licenses/by/4.0/). 